\title{
EL TRÁNSITO DE ARGELINOS POR EL PUERTO DE ALICANTE ${ }^{1}$
}

\author{
Juan David Sempere Souvannavong
}

\section{RESUMEN}

La larga relación que durante siglos ha mantenido Alicante con Argelia (especialmente con la ciudad de Orán) se reduce en la actualidad a meros intercambios privados y comerciales a través de la línea marítima que une ambas ciudades. Esta línea conoce sin embargo un considerable auge cuyas causas se derivan de la crisis en Argelia: el cierre de la frontera con Marruecos y el aumento de las exportaciones de productos de consumo hacia este país. Esta coyuntura ha multiplicado el número tanto de argelinos que pasan por el puerto de Alicante para ir o volver a sus regiones de origen como el de los que vienen a abastecerse de productos de consumo en el creciente número de bazares que hay en el centro de la ciudad. Con todo ello el puerto y la ciudad de Alicante han adquirido un protagonismo importante en la movilidad de argelinos entre Europa y el Norte África, un protagonismo sin duda comparable con el nuevo papel que España está jugando en el sistema migratorio mediterráneo.

\section{RÉSUMÉ}

Alicante et l'Algérie (particulièrement la ville d'Oran) ont maintenu pendant de longues périodes une étroite relation réduite de nos jours à de simples échanges privés et comerciaux à travers la ligne maritime unissant ces deux villes. Cette ligne connaît pourtant un succès considérable dont les causes sont liées à la crise que traverse l'Algérie: fermeture de la frontière avec la Maroc et croissance des exportations de produits de consommation vers ce pays. Cette situation a multiplié le nombre d'algériens qui transitent par le port d'Alicante pour aller ou revenir à leurs régions d'origine et celui de ceux qui viennent acheter des produits de consommation dans les bazars du centre ville. La port et la ville d'Alicante acquièrent dans cette évolution un rôle important dans la mobilité des algériens entre l'Europe et l'Afrique du Nord, un rôle sans doute comparable à celui que l'Espagne joue dans le système migratoire méditerranéen.

1 Esta investigación se ha realizado dentro del proyecto SEC 98-0628 que realiza el Departamento de Geografía Humana de la Universidad de Alicante sobre inmigrantes africanos en la fachada mediterránea de España. 
Desde los años de la descolonización los contrastes sociales, económicos y demográficos no han dejado de crecer entre ambos lados del Mediterráneo Occidental. Este mar se ha transformado en una región de desencuentros y en una afilada frontera que separa la cada vez más rica y envejecida Unión Europea del Magreb, un polo de fuerte emigración con graves crisis sociales.

Por su proximidad física y natural, Alicante y Argelia han mantenido durante largas épocas intensas relaciones a través de sus conexiones marítimas. Tanto los argelinos de ahora como los franceses de antes de la independencia (1962) han conservado a lo largo de los dos últimos siglos un considerable peso específico en esta ciudad y en su región de la misma manera que los alicantinos tuvieron en su tiempo una presencia más que notable en Argelia. En nuestros días el proceso de integración europea está haciendo de Alicante una ciudad cada vez más europea y al mismo tiempo una importante ciudad con frontera, con una frontera líquida por la que cada año transita una gran cantidad de bienes, de productos y un creciente número de argelinos que vienen a realizar compras o que llegan desde sus lugares de residencia en Europa para ir a pasar las vacaciones en sus regiones de origen.

Esta situación tiene su origen en la evolución social y económica de España y de Argelia durante las dos últimas décadas así como en la existencia de un contacto regular: el barco Orán-Alicante. Esto ha dado lugar a un trasiego especial de mercancías y personas en el que se distinguen dos fenómenos claramente diferenciados. Por un lado, el incremento del tránsito de inmigrados ${ }^{2}$ argelinos en Europa que cada verano eligen Alicante para embarcarse hacia sus vacaciones en Argelia y, por otro, la movida de comerciantes ${ }^{3}$ y transportistas argelinos que a lo largo del año vienen a abastecerse de «productos de consumo occidentales» para revenderlos en una sociedad argelina ávida de todo este tipo de importaciones.

\section{1. «El barco de Orán»}

\subsection{Orán y Alicante: dos ciudades hermanadas}

La fortísima emigración levantina a la Argelia colonial, que perduró hasta el final de la Guerra Civil Española, hizo que, desde mediados del siglo XIX, los alicantinos tuvieran una vinculación estrecha y continuada con Argelia, en particular con la región y la ciudad de Orán que se encuentra a tan sólo 140 millas náuticas de Alicante. A principios de los años 1930 esta situación de proximidad dio lugar a importantes intercambios que alcanzaron el ámbito administrativo. Sin embargo, desde entonces, las relaciones han estado entrecortadas de largas crisis políticas.

Tras el largo paréntesis de la Guerra Civil y de la posguerra mundial, la relación se institucionalizó con los viajes de varias comisiones municipales entre Orán y Alicante a partir de 1952. Pero esta fase terminó cuando una década después, en 1962, Argelia se independizó de Francia y se transformó en una república socialista y musulmana. Durante

2 Los argelinos residentes en Europa, y sobre todo en Francia, se considerarán en este artículo inmigrados y no inmigrantes por que en este último país se les llama immigrés y por que se trata de una población llegada en gran parte durante la década de los años 1960 y 1970, establecida en el país de acogida con una importante segunda generación nacida ya en el mismo país.

3 «Comerciantes» es como honradamente se autodenominan todos los argelinos que vienen a Alicante a comprar; sin duda para marcar las diferencias con los inmigrados y con los prejuicios negativos que tiene la línea marítima en la sociedad alicantina. Pero entre dichos «comerciantes» cabe distinguir por lo menos entre los que trabajan por cuenta propia, que son verdaderos comerciantes, y los que lo hacen por cuenta ajena que son transportistas. 
varios años se interrumpió el barco y no hubo ninguna relación entre Alicante y Orán. En los años 1980 se renovaron los contactos municipales impulsados en particular por la iniciativa del Alcalde Don José Luis Lassaletta ${ }^{4}$ que culminaron con la firma del hermanamiento entre Orán y Alicante el 27 de junio de 1985. Durante los 3 años siguientes se dieron una serie de intercambios ante todo culturales que fueron interrumpidos con la suspensión de la línea marítima Alicante-Orán en octubre de 1988. Aunque en febrero de 1989 se reanudaron los trayectos marítimos, las administraciones de ambas ciudades prácticamente no han vuelto a tener contactos.

En la década de los años 1990 se ha producido al menos un intento de retomar los contactos en el marco del hermanamiento, pero de momento estos no han pasado de una mera declaración de intenciones ${ }^{5}$. Los problemas políticos que desde 1988 sufre Argelia y la falta de iniciativa por parte alicantina impiden toda aproximación y explica el que las administraciones no tengan, ni parece que vayan a tener, participación alguna en la relación entre ambas ciudades. Esta relación se reduce pues al ámbito privado y comercial, al intercambio espontáneo y natural que pueda darse entre dos regiones tan distintas y tan cercanas. En la actualidad hay además una última dificultad, y es que todo este movimiento se da prácticamente en un sólo sentido: desde el principio de la crisis y sobre todo desde que en el verano de 1994 los occidentales empezaron a ser asesinados en Argelia, ningún español realiza el viaje sin motivos de peso.

A pesar de estos inconvenientes, el número de argelinos que transitan por el puerto de Alicante se ha disparado en los últimos tiempos y sigue aumentando de año en año (gráfico 1). Por una parte los inmigrados en Europa que pasan por Alicante para ir de vacaciones a sus regiones de origen se han multiplicado mientras que por la otra la crisis de este país ha mejorado los beneficios de la importación de productos de consumo a este país y en consecuencia el movimiento de comerciantes y de transportistas.

\subsection{Un contexto político e internacional especialmente favorable}

Los datos facilitados por la Autoridad Portuaria de Alicante han permitido elaborar un gráfico que revela la evolución del movimiento internacional de pasajeros y vehículos por el puerto de Alicante desde mediados de los años 1980. Siendo el «barco de Orán» la única línea regular de pasajeros que tiene el puerto de Alicante (a parte de la que va a la isla de Tabarca) estos datos se refieren exclusivamente al intercambio con Argelia ${ }^{6}$. El periodo reflejado muestra un desarrollo irregular que en los últimos años se ha incrementado de manera regular y contundente hasta superar en 1999, último año disponible, 213.000 pasajeros registrados. Durante las dos últimas décadas las causas políticas han jugado un papel preponderante en esta evolución, las vicisitudes políticas de España, y sobre todo de Argelia justifican en buena parte las irregularidades más llamativas del gráfico 1.

A partir de 1988/89 se dan cambios importantes en la evolución de esta línea marítima; sus causas, sin duda diversas, están ligadas a la desestabilización que Argelia empezó a tener a partir de las revueltas urbanas de octubre de 1988. La violencia y la inseguridad

4 Don José Luis Lassaletta fue, entre 1978 y 1991, el primer Alcalde de Alicante en la democracia. Cuatro de los nueve hermanamientos que tiene actualmente la ciudad de Alicante se realizaron bajo su gobierno.

5 Nos referimos a una carta enviada a mediados de 1993 por el Ayuntamiento de Alicante al de Orán, interesándose por la renovación de las relaciones y la respuesta, en septiembre de 1993, en la que la Delegación Ejecutiva Comunal de Orán está «enteramente dispuesta a reanudar y a reforzar los lazos de amistad previstos en el marco del hermanamiento».

6 En el puerto de Alicante hacen escala un creciente número de cruceros, pero sus pasajeros son contabilizados como tránsito y no como movimiento internacional. 


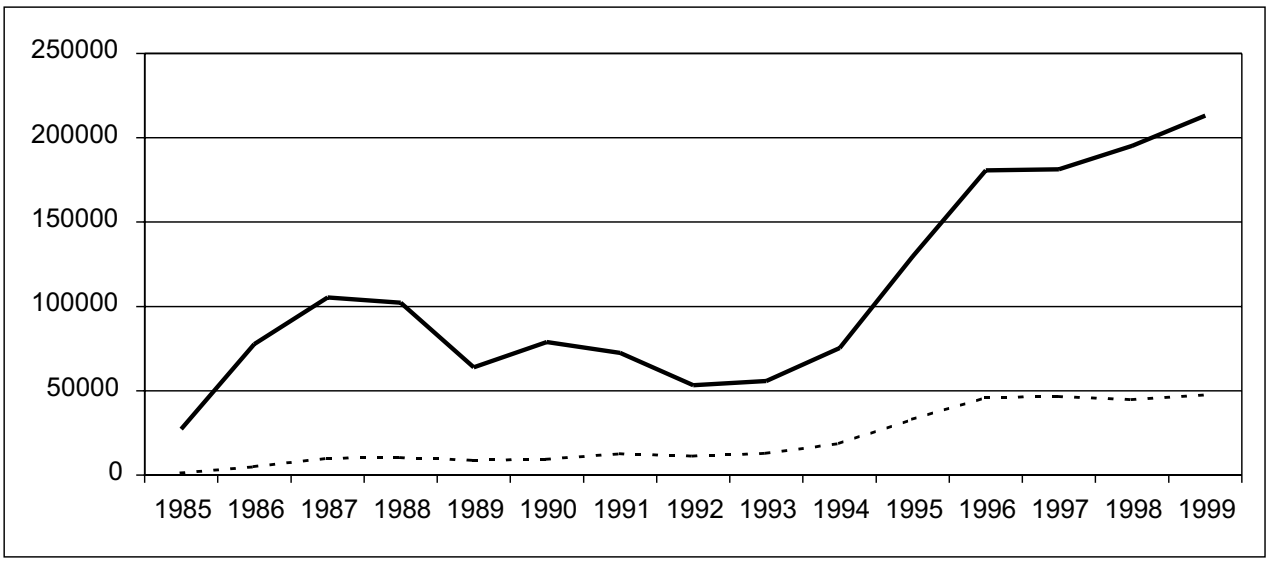

GrÁFICO 1. Movimiento internacional de pasajeros (línea continua) y de vehículos (línea discontinua) por el puerto de Alicante entre 1985 y 1998. Fuente: Autoridad Portuaria de Alicante.

— que este país había desconocido desde su independencia en 1962 - enfriaron las relaciones y el movimiento tanto de inmigrados como de comerciantes. La línea marítima Alicante-Orán estuvo de hecho suspendida entre el 11 de octubre de 1988 y el 18 de febrero de $1989^{7}$ por orden de las autoridades argelinas, que con este golpe pretendieron minimizar, de manera vistosa, los contactos entre Argelia y el extranjero desde donde se denunciaba que se dirigían los disturbios ${ }^{8}$.

En 1990 y 1991 se observa una recuperación vacilante del tránsito de argelinos por Alicante; son los años de la «Guerra del Golfo» y sobre todo los de un difícil despertar político de la sociedad argelina, con grandes huelgas, manifestaciones y los primeros enfrentamientos entre el ejército y el Frente Islámico de Salvación. Se trata en general de una degradación y un «calentamiento» del ambiente que desembocaría en la guerra entre el poder y los islamistas, lo que impide que el tránsito recobre la intensidad que tenía antes de 1988.

La imposición del visado de entrada (a partir del 15 de mayo de 1991) por parte de España a los ciudadanos de un gran número de países, entre ellos los del Magreb, marca un giro evidente y decisivo en la política española hacia la integración en Europa y la restricción de las entradas provenientes de países más pobres. Este hecho justifica el descenso en el tráfico marítimo de pasajeros que se vuelve a dar de 1991 a 1994; esta medida redujo sobre todo la llegada de turistas argelinos. No se puede afirmar, sin embargo, que la necesidad de visado limitará de manera decisiva el tránsito de argelinos por Alicante, en particular para el comercio y transporte de mercancías. Siendo éste un negocio

7 El domingo 9 de octubre de 1988 el gobierno argelino envió a la empresa consignataria de la línea un telex en el que, sin más explicaciones, se le comunicaba que la línea Alicante-Orán quedaba suspendida hasta nueva orden. El diario Información de Alicante del día siguiente señala, sin dar demasiadas explicaciones, que la suspensión de la línea marítima se debe a la revuelta. Aparentemente no relaciona esta suspensión con el titular que en su primera página y a cuatro columnas había publicado el día anterior, el 8 de octubre: «El MDA en Alicante asegura dirigir la revuelta de Argel» (MDA: Movimiento para la Democracia de Argelia).

8 Las comunicaciones telefónicas también estuvieron sospechosamente cortadas durante esos días (Información de Alicante, 8-10-1988). 
rentable y bien rodado, el visado es una dificultad suplementaria que debió ser fácilmente superada por parte de los importadores y de las redes informales en las que se apoyan. El descenso que se aprecia en estos años se debe seguramente menos a la imposición del visado que a la fuerte inestabilidad que ya conocía Argelia, y que justifica la disminución de los pasajeros argelinos y el desvanecimiento de la presencia extranjera en este país.

En realidad toda la fase que se desarrolla entre 1988 y 1994 puede ser considerada como una única etapa en la que las irregularidades están dictadas primero por la efervescencia política en Argelia, y luego por el estado de guerra civil. Desde entonces, aunque estos factores no desaparecen en absoluto, se produce un cambio radical que, como se ve en el gráfico, solapa por completo la situación anterior, multiplicándose a partir de $1994 \mathrm{el}$ número de personas y de vehículos que transitan por el puerto de Alicante.

Es cierto que la guerra civil argelina se banalizó y se desplazó a las zonas rurales dejando las grandes ciudades fuera de la zona más conflictiva, pero el hecho decisivo se produjo el 27 de agosto de 1994 cuando Argelia cerró su frontera terrestre con Marruecos 9 . Hasta entonces la mayoría de los argelinos inmigrados que pasaban por España para volver a sus regiones de origen tomaban el barco de Almería o de Málaga a Melilla, para seguir por carretera hasta Argelia. Este incidente interrumpió el paso legal y aparente de personas y mercancías por la frontera, con lo que Marruecos dejó de ser un país de tránsito hacia Argelia y Almería dejó de ser el puerto de paso. Este hecho coyuntural ha puesto a Alicante -único puerto español desde donde embarcarse hacia este país- en pleno eje circulatorio entre Argelia y Europa. El residente argelino en Europa que desea ir (en familia y con el coche $^{10}$ a su país debe hacerlo por vía marítima ${ }^{11}$, puede embarcarse en Marsella, en Sète, en Alicante o en Italia (Génova, Nápoles o en Sicilia). De estas alternativas la más barata, sobre todo si se dirige al oeste de Argelia, es la de Alicante. A una familia le resulta menos rentable tomar el barco de Marsella a Argelia, donde cada miembro debe pagar un pasaje además del coche, que venir por carretera hasta Alicante (aunque la autopista sea de peaje) y embarcarse hacia Argelia por el trayecto marítimo más corto posible que hay en la actualidad. Generalmente cuanto más corto sea el trayecto en barco más se ahorra en el viaje de Europa a Argelia; y conviene ahorrar ya que en el Magreb las monedas europeas multiplican su poder adquisitivo.

Esta coyuntura circunstancial emanada de las susceptibilidades entre Argelia y Marruecos añadida a los diversos problemas existentes en los puertos del sur de Francia ${ }^{12}$, ha obligado a muchos inmigrados argelinos a descubrir y consolidar la alternativa de Alicante lo que ha transformado el panorama del tránsito de los magrebíes en el Mediterráneo. A

9 El 24 de agosto de 1994 dos turistas españoles murieron en un atentado en Marrakech y las autoridades marroquíes declararon que los autores eran argelinos. Tras el cruce de acusaciones Marruecos exigió, el 26 de agosto, el visado a los ciudadanos argelinos con lo que al día siguiente Argelia cerró su frontera terrestre con Marruecos. Desde entonces y a pesar de los momentos de aproximación y de expectativa la frontera ha seguido cerrada.

10 La importancia del automóvil es transcendental tanto para transportistas como para inmigrados; para los primeros es de gran necesidad para el transporte de sus mercancías, y para los segundos, además, sigue siendo todo un símbolo del éxito social y laboral que debe ser ostentado en la región de origen [CHAREF, 1998, 219237].

11 Es obvio que en la actualidad, además del ferry, existe el avión. Alicante es el único aeropuerto español que tiene conexiones semanales con Argel y Orán. Sin embargo este medio de transporte tiene, para el tránsito que estudiamos, un alcance mucho menor, afecta a un número muy inferior de mercancías y de personas (menos de 16.000 entradas y salidas en 1998) y sobre todo presenta, por encima del precio, la desventaja de no poder transportar el automóvil. El avión concierne a otra categoría de tránsito

12 El número de pasajeros magrebíes que transita por el puerto de Marsella está en descenso desde el final de los años 1980. Sólo entre 1996 a 1997 se ha reducido en un 8\%, pasando de 234.000 a 214.000. 
pesar de su reducida participación en el movimiento general, Alicante se ha convertido en uno de los puertos clave de la Operación Paso del Estrecho y de la circulación de personas en el Mediterráneo.

\subsection{Un servicio sin competencia}

Mientras dure esta coyuntura el trayecto más corto y más barato para ir al oeste de Argelia desde Europa seguirá pasando por Alicante. Esto produce un transvase de pasajeros y de beneficios que recalan en los distintos agentes que se ocupan de esta línea (la naviera, la empresa consignataria, la autoridad portuaria y algunos comercios alicantinos) que ahora tramitan la integridad de los movimientos de pasajeros que van o vienen de Argelia desde cualquier zona de España y de otros muchos que vienen de Europa. Es una inmejorable situación que por una parte aporta grandes beneficios pero que por otra viene a compensar justamente la incertidumbre de no saber cuando las autoridades van a cortar arbitrariamente este tráfico sin compensación alguna ${ }^{13}$.

L'Entreprise Nationale des Transport Maritime de Voyageurs (ENTMV), una de las empresas argelinas estatales de transporte marítimo, es la compañía que en la actualidad cubre la línea regular entre Alicante y Argelia. Desde que antes de la Guerra Civil la empresa española Trasmediterránea dejó de hacer estos trayectos, esta línea sólo ha estado a cargo de empresas argelinas (o francesas antes de la independencia). A Alicante vienen cuatro buques de la ENTMV de características similares ${ }^{14}$ : El-Djazair, Hoggar, Tipasa y Zeralda; realizan el viaje a Orán. La misma naviera realiza un servicio quincenal entre Argel y Alicante y otro entre Marsella y Alicante que luego va a Orán, este recorrido lo suele realizar un quinto barco, el Tariq Ibn Ziyad, más moderno y con más capacidad lo que reduce el colapso veraniego en el puerto de Alicante.

Existe un fuerte desequilibrio en el servicio que se ofrece en verano - la temporada alta- respecto al que hay durante el resto del año: en julio y agosto son 31 ó 32 las rotaciones que se efectúan mientras que en octubre y noviembre se reducen a 14 ó 15 y en enero y febrero a $10 \mathrm{u} 11$. Estas diferencias se deben evidentemente a las fuertes variaciones estacionales de la demanda, sin duda una de las principales dificultades a las que deben enfrentarse las compañías que cubren los trayectos del Mediterráneo. En verano el servicio es a menudo insuficiente, aunque se pongan muchos más medios es corriente que bastantes coches no puedan embarcar ${ }^{15} \mathrm{y}$ deban esperar hasta el barco siguiente ${ }^{16}$. Lo curioso es que en invierno también se ha observado este hecho, hay barcos que salen completos ${ }^{17}$ cuando en esa época sólo hay una o dos rotaciones por semana. Esto revela que, sea o no por la escasez de medios, la falta de transporte que ofrece la compañía es una constante tanto en temporada alta como en invierno. Es probable que este desequilibrio en la oferta se deba

13 Durante la interrupción de 1988 los responsables de la empresa consignataria declararon que en el contrato no estaba prevista ninguna compensación para esa situación (Información de Alicante, 12-10-1988).

14 Tonelaje de unas 10.000 toneladas y unos 120 metros de eslora.

15 En la demanda de este barco, como en la de todos los ferrys, hay dos clases distintas que no pueden ser mezcladas: la de pasajeros y la de vehículos. Debido a la importancia, ya resaltada, de los vehículos en este tipo de tránsito, el problema en esta línea es, tanto en verano como en invierno, más la falta espacio para los coches y las furgonetas que para las personas.

16 Bastantes personas interrogadas, sobre todo comerciantes, han declarado que con un pequeño suplemento es fácil solventar esta espera.

17 No es raro que algunos coches no puedan embarcar y se tengan que quedar en Alicante hasta el barco siguiente. Las críticas a la ENTMV y a la situación de monopolio que tiene están bastante generalizadas entre los viajeros consultados. 
también a factores ajenos al beneficio y a la pura demanda. La empresa está sin duda interesada en mejorar el servicio de invierno cuando predominan los transportistas y los barcos hacen el viaje de ida y de vuelta igual de cargados, algo que en verano no sucede. Pero al ser ENTMV una empresa estatal, está seguramente sometida a una política y a unas estrategias que son las del Estado, y parece normal que a éste le interese más facilitar la entrada estival de inmigrados y de sus suculentas divisas que mejorar el servicio para la importación de unos productos que, todo el mundo lo sabe, se van a «colar» de contrabando por todo el país. Está claro que la demanda, la rentabilidad y las expectativas podrían justificar una ampliación de esta línea hasta convertirla en un verdadero puente entre España y Argelia, sin embargo está aún más claro que las voluntades políticas no van encaminadas precisamente en esa dirección, ni por parte argelina, ni como vamos a ver, por parte española.

\subsection{La indiferencia por parte alicantina}

A pesar de su antigüedad y de la movilización que conlleva, la pervivencia de la línea entre Orán y Alicante no despierta entre la gran mayoría de los alicantinos interés especial. En la actualidad son más de 150 los barcos que anualmente vienen de Argelia, lo que correctamente administrado representa para la ciudad y para su comercio un flujo potencial de personas muy considerable que precisamente vienen a comprar. Sin embargo la población local desconoce casi todo de este barco, de su pasado y de lo que sucede en su lugar de origen. Fuera del reducido grupo de personas - en gran medida musulmanas - que trabajan más o menos directamente con los argelinos, el único contacto que tienen los alicantinos con el barco y sus pasajeros es generalmente cuando los ven deambular por las calles de los bazares o a través de los medios de comunicación, que sólo se acercan a este tránsito cuando la Unidad de Protección Civil de la subdelegación del Gobierno Civil rinde cuentas sobre la Operación Paso del Estrecho o cuando regularmente surge algún escándalo sobre el tráfico de coches robados en Europa, las condiciones de espera o la huida de algún polizón que intenta entrar en Occidente. Dos razones pueden justificar esta ignorancia: la relativa discreción de los argelinos y la profunda indiferencia por parte alicantina.

Los miles de argelinos procedentes de Europa que transitan por Alicante tienen una penetración bastante efímera en la ciudad, el uso que la mayoría de ellos hace del tiempo y del espacio está generalmente restringido a algunas horas del día y a las zonas próximas al puerto. Una costumbre de estos inmigrados, en su mayoría familias, es que no se suelen separar nunca de sus sobrecargados vehículos; una vez que llegan al puerto se quedan junto a los coches en la zona de espera, con lo que lo normal es que no aparezcan por la ciudad durante su permanencia en Alicante. La existencia de una travesía directa y señalizada que llega al puerto desde la salida de la autopista de Francia, sin llegar a entrar en la ciudad, evita muchos de los incidentes, particularmente en el tráfico urbano, que cabría esperar del paso de miles de coches extranjeros en pocos días.

Los transportistas, por su parte, se mueven bastante más por la ciudad, pero la mayoría lo hace durante las horas que vienen a comprar y por calles muy concretas del centro donde se concentran los bazares, pensiones, bares y restaurantes a los que van casi siempre. Hay pues una separación clara del espacio cuyo caso más paradigmático es el muelle de Levante, donde se ubica la estación portuaria. La cara interior del muelle es de noche una de las zonas de ocio más activas de la ciudad, mientras que a escasos metros, en la parte exterior, se encuentra la zona en la que durante el día los argelinos esperan y por donde se mueven cuando van y vienen de la ciudad a la estación portuaria. 
A la discreción con que se comportan la mayoría de los argelinos cabe añadir la escasa atención que les prestan la población y las instituciones autóctonas. Esto se debe a que los españoles han dejado de viajar a Argelia y sobre todo a un cierto rechazo latente en sectores de la población local hacia este barco argelino que sólo parece traer problemas. Es bastante frecuente que a este nivel dominen los prejuicios y se confunda a los comerciantes argelinos que transitan por Alicante con el cada vez más espinoso tema de la inmigración. El barco viene efectivamente acompañado «de cierta polémica entre los representantes públicos sobre cuestiones de seguridad ciudadana». Aunque, tras la última suspensión de la línea, la policía dejó claro que la presencia o la ausencia de argelinos no guarda relación con el incremento o el descenso de la delincuencia (Información de Alicante, 19-2-89), la aprensión, los pequeños incidentes y los delitos menores no dejan de alimentar los estereotipos que sobre los moros tienen los euro-españoles. A principios de la década de los años 1990 la fuerte resistencia municipal hizo fracasar el intento de crear una línea Alicante - Nador, que finalmente se fue a Almería. Por otra parte las asociaciones de comerciantes del centro de la ciudad presionaron para que la estación portuaria fuera trasladada a la lejana nueva zona portuaria de poniente, totalmente fuera del casco urbano. Este cambio hubiera alterado por completo el tránsito de magrebíes por el centro de la ciudad. Estos detalles recuperados, pueden ilustrar el rechazo de ciertos sectores así como la indiferencia general de los ciudadanos en todo lo que respecta al «barco de Orán».

Estas reacciones contrastan con el comportamiento que, según personas interrogadas, hay en Orán con respecto a esta misma línea marítima. Para esta ciudad el barco, aunque en él no vengan más que argelinos, representa la llegada de varios cientos de personas desde Alicante, lo que significa una conexión, un vínculo directo con Occidente. Aunque es obvio que la radio, los inmigrados de Francia y ante todo las antenas parabólicas ejercen de nexos fundamentales con Europa, el barco de Alicante representa además una entrada real y directa de los productos y de la moda occidental que tanto apetecen en la sociedad argelina y especialmente en la juventud de este país. El barco es además un elemento en torno al que trabaja y vive, directa o indirectamente, un colectivo de personas mucho más numeroso que en Alicante. Todo esto justifica en buena medida que un entrevistado declarara: «la juventud oranesa intenta calcar a la juventud alicantina», lo que bien puede resumir algunos de los sentidos que conserva este barco en Orán.

\section{El tránsito estival de argelinos por el puerto de Alicante: la operación paso del estrecho}

\subsection{El movimiento Europa - Magreb}

A pesar de que en estos años está creciendo mucho el número de residentes magrebíes en España, este país sigue siendo ante todo una región de tránsito para muchos de ellos. Si nos fiamos de las cifras oficiales, a finales de 1998 había en España $7.043^{18}$ residentes argelinos, mientras que fueron casi 200.000 los que transitaron sólo por Alicante durante ese mismo año. Aunque es lógico pensar que el número real de argelinos que viven en España es mucho mayor, por el momento son muchos más los que no hacen más que transitar para ir de Europa a sus regiones de origen.

Las grandes fiestas del calendario musulmán son, junto al verano, las épocas en las que los argelinos más cruzan España. La temporada estival es obviamente la más concurrida,

18 Anuario Estadístico de Extranjería de 1998. Comisión Interministerial de Extranjería, Madrid. 
algo más de la mitad de los pasajeros que transitan anualmente por el puerto de Alicante se concentran sólo en los tres meses de verano. Es cuando se pone en marcha la Operación Paso del Estrecho y cuando se suceden la mayoría de los acontecimientos que despiertan interés y alcanzan a los medios de comunicación.

Hasta fechas recientes Francia era el destino casi exclusivo de la emigración magrebí a Europa. Desde los años 1950 y 1960 los argelinos han sido uno de los colectivos de residentes extranjeros más importante de Francia $^{19}$. Por su posición geográfica España y Alicante se encuentran en el eje circulatorio entre Europa y el Magreb, pero hasta la década de los años 1980 no han cobrado importancia como región de tránsito ni para marroquíes ni para argelinos. Esto se debe por una parte, a que Marruecos sólo se ha transformado en un auténtico país de emigración desde los años 1970 y, por la otra, a que en Argelia los focos tradicionales de emigrantes están en la zona central del país, lejos de Orán, y cerca de puertos importantes como Annaba, Skikda y sobre todo Argel y Bejaïa que tienen enlaces marítimos directos con Francia.

No es sino en las últimas décadas cuando - a pesar de las crecientes restricciones- la emigración internacional se ha generalizado en casi todo el Magreb y cuando los residentes magrebíes han ido apareciendo en otros países europeos como Holanda, Bélgica e Italia. En los años 1980 y 1990 el grado de integración que han terminado adquiriendo muchos inmigrados en las sociedades europeas, se ha conjugado con el abaratamiento, el desarrollo y la banalización de los medios de transporte para facilitar el retorno anual de un número creciente de magrebíes a sus regiones de origen. Lo que empezó siendo sólo un movimiento de argelinos entre Francia y Argelia a través de Marsella o Sète, se está transformando cada vez más en un movimiento de magrebíes entre Europa y el Norte de África a través de España.

En la actualidad hay en Europa unos 700.000 inmigrados argelinos, casi todos en Francia $^{20}$. En este país residen según el último censo publicado (1991) ${ }^{21}$ unos 614.000 argelinos que pasan a ser 725.000 si contamos a los franceses de origen argelino, generalmente inmigrados nacionalizados o hijos de inmigrados. Los marroquíes y franceses de origen marroquí son más de 640.000 en Francia y en el resto de los países europeos son casi 600.000 personas, principalmente repartidas por Holanda (136.000), Bélgica (133.000), Italia (131.000) y España (111.000) ${ }^{22}$. Es decir, en Europa y sólo oficialmente, hay casi dos millones de inmigrados magrebíes o hijos de inmigrados susceptibles de regresar periódicamente a sus regiones de origen. El tránsito estival de argelinos y marroquíes por España es pues un movimiento que, como muestra el cuadro 1 , concierne a muchos cientos de miles de personas.

La magnitud de este fenómeno revela la importancia del apego que a pesar del tiempo mantienen los emigrados magrebíes hacia sus sociedades de origen. Hay que señalar que, hasta los años 1980 el retorno anual de los inmigrados al Norte de África era correspondido con un número sensiblemente equivalente de magrebíes que iban a visitar a sus familias emigradas a Europa [SIMON, 1995: 350]. La circulación de personas a través del Mediterráneo era un flujo que funcionaba en los dos sentidos, pero en 1986 Francia impuso el visado de entrada a los magrebíes entorpeciendo sus viajes a Europa. Desde entonces, para

19 Según los censos franceses el número de residentes argelinos pasó de 211.675 en 1954 a 710.690 en 1975 y a 805.116 en 1982.

$20 \mathrm{El}$ resto de los argelinos en Europa se distribuyen en un número mucho más reducidos por países como Bélgica (unos 9.000) y España (7.043).

21 En 1999 se realizó un nuevo censo en el que es probable que la población magrebí se haya incrementado.

22 SOPEMI (OCDE): Tendances des migrations internationales. Rapport annuel, Ed. OCDE, 1999. 
ver a sus familias los inmigrados argelinos o marroquíes están prácticamente obligados a regresar a su país, y en consecuencia a embarcarse en los puertos que tienen líneas marítimas con el Magreb: Sète, Marsella, Algeciras, Málaga, Almería o Alicante.

\subsection{La Operación Paso del Estrecho}

El paso de magrebíes por España es pues tan antiguo como la presencia magrebí en Europa; sin embargo, al igual que está sucediendo con la inmigración, no se ha tomado conciencia de este hecho hasta fechas muy recientes, a mediados de los años 1980, cuando las dificultades que conllevaba este tránsito crecieron en importancia. Los problemas que las huelgas y la falta de previsión provocaron en esta década, transformaron el paso estival de magrebíes en un «asunto de Estado» [LÓPEZ GARCÍA, 1996: 252], y obligaron a las autoridades españolas y marroquíes a coordinarse para organizar el tránsito y el embarque de los cientos de miles de personas que llegaban a los puertos del Estrecho en pocas semanas. Lo que empezó siendo una simple colaboración en 1983 entre la Dirección General de Tráfico y la Embajada de Marruecos en Madrid [CHAREF, 1999: 23], se transformó a partir de 1987 en toda una operación entre los puertos del Estrecho (Ceuta, Tánger y Algeciras), denominada «Operación Tránsito» y dirigida por la Dirección General de Protección Civil Española. A partir de 1991 pasó a ser la «Operación Paso del Estrecho» a la que se han ido sumando los puertos de Melilla, Málaga, Almería y finalmente Alicante. Con ello, la Operación, que ya excede ampliamente el ámbito del Estrecho, abarca la totalidad de los puertos españoles que tienen líneas regulares de pasajeros con el Magreb.

La Operación se divide en dos períodos que se solapan: la fase de salida del 15 de junio al 15 de agosto, y la fase de regreso del 15 de julio al 15 de septiembre. En líneas generales consiste en coordinar las diversas instituciones y administraciones y en tomar una serie de medidas encaminadas a regular la llegada masiva de inmigrados. Entre estas medidas destacan las asistencias sanitarias y sociales (accidentes, averías, pérdidas, traducciones...), la regulación del tráfico y el control de los pasos fronterizos con Francia, lo que permite prever los momentos de máxima afluencia con varias horas de antelación ${ }^{23}$.

Los gastos de la Operación están entorno a los 500 millones de pesetas, y aunque no se suelen producir graves incidentes en la memoria realizada por la Dirección General de Protección Civil se advierte que algunos puertos han llegado a su máxima capacidad y que ésta tendrá que ser mejorada, particularmente en los puertos norteafricanos, tanto españoles como marroquíes.

Cada año el número de pasajeros que cruzan el Estrecho en el marco de esta Operación supera ampliamente el millón de personas y va en aumento. Lógicamente esta cifra engloba a todos aquellos que van o vienen del Magreb por vía marítima y regular. Esto quiere decir que también se incluye un número, en absoluto despreciable, de personas que no son inmigradas en Europa: a los comerciantes especialmente importantes en el caso de Alicante, a los residentes en el Norte de África — particularmente en Ceuta y Melilla ${ }^{24}$ — y a los turistas europeos que durante las vacaciones viajan en masa a Marruecos.

23 Por parte francesa colabora el Fonds d'Action Social (FAS) y por parte marroquí varias instituciones entre las que destaca la Gendarmería Real, la Media Luna Roja Marroquí, la Subsecretaría de Estado encargada de la Comunidad Marroquí en el Extranjero y la Fundación Hassan II para los Residentes Marroquíes en el Extranjero.

24 Los habitantes de Ceuta y Melilla se embarcan frecuentemente hacia la península cuando disponen de algún día de vacaciones. Para ello tienen hasta la costumbre de dejar los coches en Algeciras y Almería durante la semana. 
Cuadro 1

TOTAL DE PERSONAS Y VEHÍCULOS (EN MILES) QUE HAN CRUZADO EL ESTRECHO DURANTE LA OPERACIÓN PASO DEL ESTRECHO (1994-99)

\begin{tabular}{|c|c|c|c|c|c|c|c|c|c|c|c|c|}
\hline Año & \multicolumn{2}{|c|}{1994} & \multicolumn{2}{|c|}{1995} & \multicolumn{2}{|c|}{1996} & \multicolumn{2}{|c|}{1997} & \multicolumn{2}{|c|}{1998} & \multicolumn{2}{|c|}{1999} \\
\hline Líneas & Veh. & Pers. & Veh. & Pers. & Veh. & Pers. & Veh. & Pers. & Veh. & Pers. & Veh. & Pers. \\
\hline Algeciras - Ceuta & 66 & 356 & 53 & 290 & 53 & 296 & 58 & 275 & 59 & 316 & 62 & 329 \\
\hline Ceuta - Algeciras & - & - & 57 & 302 & 60 & 323 & 65 & 287 & 67 & 342 & 74 & 369 \\
\hline Algeciras - Tánger & 85 & 352 & 76 & 301 & 86 & 339 & 97 & 331 & 95 & 356 & 105 & 407 \\
\hline Tánger - Algeciras & - & - & 63 & 261 & 74 & 292 & 83 & 293 & 84 & 363 & 88 & 373 \\
\hline Málaga - Melilla & 13 & 55 & 10 & 44 & 9 & 36 & 7 & 26 & 7 & 27 & 6 & 25 \\
\hline Melilla - Málaga & - & - & 10 & 47 & 9 & 39 & 7 & 33 & 9 & 37 & 7 & 35 \\
\hline Almería - Melilla & 18 & 75 & 12 & 57 & 14 & 67 & 8 & 32 & 12 & 51 & 8 & 31 \\
\hline Melilla - Almería & - & - & 10 & 51 & 13 & 62 & 6 & 27 & 9 & 39 & 7 & 26 \\
\hline Almería - Nador & - & - & 9 & 43 & 11 & 54 & 29 & 128 & 28 & 126 & 41 & 178 \\
\hline Nador - Almería & - & - & 9 & 46 & 10 & 47 & 26 & 126 & 25 & 123 & 33 & 159 \\
\hline Alicante - Orán & - & - & - & - & - & - & 11 & 51 & 11 & 48 & 12 & 55 \\
\hline Orán - Alicante & - & - & - & - & - & - & 9 & 43 & 9 & 49 & 11 & 55 \\
\hline Total salida & 182 & 838 & 160 & 735 & 173 & 792 & 210 & 843 & 212 & 924 & 234 & 1.025 \\
\hline Total retorno & - & - & 150 & 707 & 166 & 763 & 196 & 809 & 203 & 953 & 220 & 1.016 \\
\hline Movimiento total & - & - & 310 & 1.442 & 339 & 1.555 & 406 & 1.652 & 415 & 1.877 & 454 & 2.041 \\
\hline
\end{tabular}

FUENTE: Resumen final de la Operación Paso del Estrecho 1999. Dirección General de Protección Civil, Madrid.

En conjunto el cuadro 1 permite destacar los rasgos de la evolución general y avanzar algunas conclusiones.

En la Operación Paso del Estrecho y en el tránsito general entre España y el Norte de África destacan tres grandes líneas (Algeciras - Ceuta, Algeciras - Tánger y Almería Nador) que en 1999 acapararon casi el 90\% de todo el tránsito de pasajeros. El resto se lo repartieron las tres líneas menores (Málaga - Melilla, Almería - Melilla, Alicante - Orán) siendo la de Alicante la más importante de ellas. La principal característica en la evolución de este tránsito es que ninguna de las cifras globales ha dejado de crecer de un año a otro; en 1999 el tránsito superó los dos millones de personas aumentando de manera muy significativa en todas las líneas menos las que conciernen al puerto de Melilla.

El predominio cuantitativo de las líneas marítimas del puerto de Algeciras es indiscutible, por este puerto transitan todos los emigrados del sur, del centro y de parte del norte de Marruecos con lo que concentra casi las tres cuartas partes de todo el tránsito de la Operación. La curiosa evolución que se observa durante los años 1995, 1996 y 1997 se debe sin duda al desvío de tráfico hecho a favor de Almería. Este puerto se ha transformado 
en el segundo más importante de la Operación (en la península), con porcentajes de pasajeros que alcanza casi la quinta parte del total. Esta situación se debe a la nueva línea entre Almería y Nador (que en un principio tenía que venir a Alicante) que se ha transformado en el gran puerto del Rif Oriental, una de las regiones de mayor emigración y una ciudad cuya desenfrenada expansión es resultado tanto de las divisas de la emigración como del retorno de la misma. El incremento del tránsito por su puerto se debe en gran medida a esta razón y también a una política de Estado que parece encaminada a transformar Nador en el gran puerto de todo nordeste de Marruecos en perjuicio de la vecina Melilla $^{25}$, un puerto cuyas conexiones marítimas con la península se están quedando sólo para los residentes de la ciudad autónoma.

Por otra parte el cuadro revela algunas disparidades que se dan sobre todo entre las cifras de salida y las de retorno. La más curiosa es la que hay entre los vehículos que van y los que vuelven: las cifras globales muestran como sistemáticamente entre un $3 \%$ y un $7 \%$ de los vehículos que van al Norte de África ya no vuelven, especialmente en la línea Tánger-Algeciras donde estas diferencias llegaron a superar en 1999 el 16\%. Las líneas que conectan la península con Ceuta y Melilla (dos territorios exentos del IVA) traen más coches de los que llevan mientras que las que unen directamente la península con Argelia o Marruecos llevan por el contrario más coches que traen (en 1999 un 16,5\% de más). Esta sospechosa desproporción, que también se da en el número de personas aunque no de manera tan acentuada ni tan regular, alcanza en valores absolutos los 14.000 vehículos (26.000 si quitamos las líneas de Ceuta y Melilla). Esto no puede sino esconder un trasvase de coches europeos hacia Marruecos y Argelia donde, al igual que sucede con muchos otros productos occidentales, el mercado está mucho más limitado y donde los automóviles europeos tanto nuevos como usados —o las piezas que los componen- suelen ser muy apreciados. Este hecho tiene que servir para hacerse una idea de las dimensiones de estas exportaciones invisibles.

\subsection{La situación estival en Alicante}

De las líneas marítimas que participan en la Operación Paso del Estrecho, la de Alicante-Orán es sin duda la más particular ${ }^{26}$. Es una travesía nocturna que une España con Argelia: un país más lejano, que se encuentra fuera del ámbito del Estrecho, y al que, debido a sus circunstancias políticas, ya no viajan occidentales, con lo que esta es la única línea que concierne casi exclusivamente a ciudadanos magrebíes.

Como se ha señalado, en 1994 las autoridades municipales alicantinas desestimaron la posibilidad de enlazar la ciudad con Nador por vía marítima. Esta nueva línea hubiera multiplicado el tránsito de magrebíes y probablemente habría transformado Alicante en el segundo puerto peninsular en embarque de magrebíes detrás de Algeciras. Desde entonces, a pesar del fuerte incremento, el tráfico marítimo por Alicante ha seguido reducido a su mínima expresión: a una media de dos rotacione ${ }^{27}$ cada tres días en la temporada alta, y entre una y tres rotaciones por semana de media durante el resto del año. Con ello Alicante ocupa, justo detrás de Málaga, la última posición entre los puertos peninsulares que

25 La modernización prevista del puerto de Tánger restará a su vez tráfico al de Ceuta.

26 Curiosamente las líneas que unen cada quince días Alicante y Argel o Alicante-Marsella no están estadísticamente incluidas en la Operación Paso del Estrecho aunque se benefician también de los servicios e infraestructuras de la Operación.

27 Por rotación se entiende, en las memorias de la Operación Paso del Estrecho, el viaje de ida y vuelta de un mismo barco. 
Cuadro 2

MEDIA DE PASAJEROS POR ROTACIÓN EN CADA UNA DE LAS LÍNEAS DE LA

OPERACIÓN PASO DEL ESTRECHO (1997-99)

\begin{tabular}{|l|r|r|r|r|r|r|r|r|r|}
\hline & \multicolumn{3}{|c|}{1997} & \multicolumn{3}{c|}{1998} & \multicolumn{3}{c|}{1999} \\
\hline Líneas & Pers. & Rot. & media & Pers. & Rot. & media & Pers. & Rot. & media \\
\hline Algeciras $\leftrightarrow$ Ceuta & 562 & 2.889 & $\mathbf{1 9 4 , 5}$ & 658 & 3.446 & $\mathbf{1 9 0 , 9}$ & 698 & 3.987 & $\mathbf{1 7 5 , 1}$ \\
\hline Algeciras $\leftrightarrow$ Tánger & 624 & 2.210 & $\mathbf{2 8 2 , 4}$ & 719 & 2.284 & $\mathbf{3 1 4 , 8}$ & 779 & 2.360 & $\mathbf{3 3 0 , 1}$ \\
\hline Málaga $\leftrightarrow$ Melilla & 59 & 126 & $\mathbf{4 6 8 , 3}$ & 64 & 158 & $\mathbf{4 0 5 , 1}$ & 60 & 126 & $\mathbf{4 7 6 , 1}$ \\
\hline Almería $\leftrightarrow$ Melilla & 59 & 169 & $\mathbf{3 4 9 , 1}$ & 90 & 228 & $\mathbf{3 9 4 , 7}$ & 57 & 176 & $\mathbf{3 2 3 , 9}$ \\
\hline Almería $\leftrightarrow$ Nador & 254 & 494 & $\mathbf{5 1 4 , 2}$ & 249 & 293 & $\mathbf{8 4 9 , 8}$ & 337 & 621 & $\mathbf{5 4 2 , 7}$ \\
\hline Alicante $\leftrightarrow$ Orán & $\mathbf{9 4}$ & $\mathbf{1 3 9}$ & $\mathbf{6 7 6 , 3}$ & $\mathbf{9 7}$ & $\mathbf{1 1 8}$ & $\mathbf{8 2 2 , 0}$ & $\mathbf{1 1 0}$ & $\mathbf{1 2 3}$ & $\mathbf{8 9 4 , 3}$ \\
\hline Movimiento total & 1.650 & 6.027 & $\mathbf{2 7 3 , 8}$ & 1.877 & 6.527 & $\mathbf{2 8 7 , 6}$ & 2.041 & 7393 & $\mathbf{2 7 6 , 1}$ \\
\hline
\end{tabular}

FUENTE: Resumen final de la Operación Paso del Estrecho 1999. Dirección General de Protección Civil, Madrid.

participan en la Operación; sólo el 5\% de los pasajeros que cruzan el Mediterráneo lo hacen por Alicante.

Lo curioso es que a pesar de esta situación la línea de Alicante-Orán es seguramente la más rentable de cuantas cruzan el Mediterráneo, por lo menos si nos fijamos en el número de personas y de vehículos que hay en cada barco. Basta con dividir el total de pasajeros por el número de rotaciones (cuadro 2) para encontrar que, con una media de casi 900 pasajeros por rotación, Alicante es, y de muy lejos, la línea que más personas transportó por barco en el verano de 1999.

El embarque de poco más de 100.000 personas en los tres meses de verano no requeriría ningún dispositivo especial de no ser por la escasez de rotaciones y la gran irregularidad que se da en la afluencia de viajeros, esta última es la característica principal de la Operación y la causa de la mayoría de las dificultades, tanto en Alicante como en el resto de los puertos. La fase de salida es la más problemática ya que es cuando se forman largas esperas para el embarque. En Alicante es la Unidad de Protección Civil de la subdelegación del Gobierno Civil la encargada de coordinar las actuaciones en las que participan esencialmente el Ayuntamiento, la Autoridad Portuaria, distintos cuerpos de policías y servicios de sanidad. El número de personas que pasan por Alicante varía enormemente de un día a otro, pero eso no se debe a tales diferencias en la afluencia de pasajeros sino a que tanto en invierno como en verano las rotaciones no son diarias. Es por lo que el gráfico 2 ofrece datos en apariencia tan irregulares.

Los datos referentes a los tres años en que Alicante ha sido incluida en la Operación evidencian claramente cómo los distintos momentos de máxima afluencia y cómo las variaciones de una semana a otra se repiten cada año de manera casi idéntica. Se pueden dar notables afluencias cualquier día, pero destacan ante todo los fines de semana que coinciden con principios, mediados y finales de mes. Los máximos absolutos en la Operación Salida se dan en todos los puertos entorno al 15 de julio o el primer fin de semana de agosto, mientras que en la Operación Retorno se dan con mucha más regularidad durante el último fin de semana de agosto. 


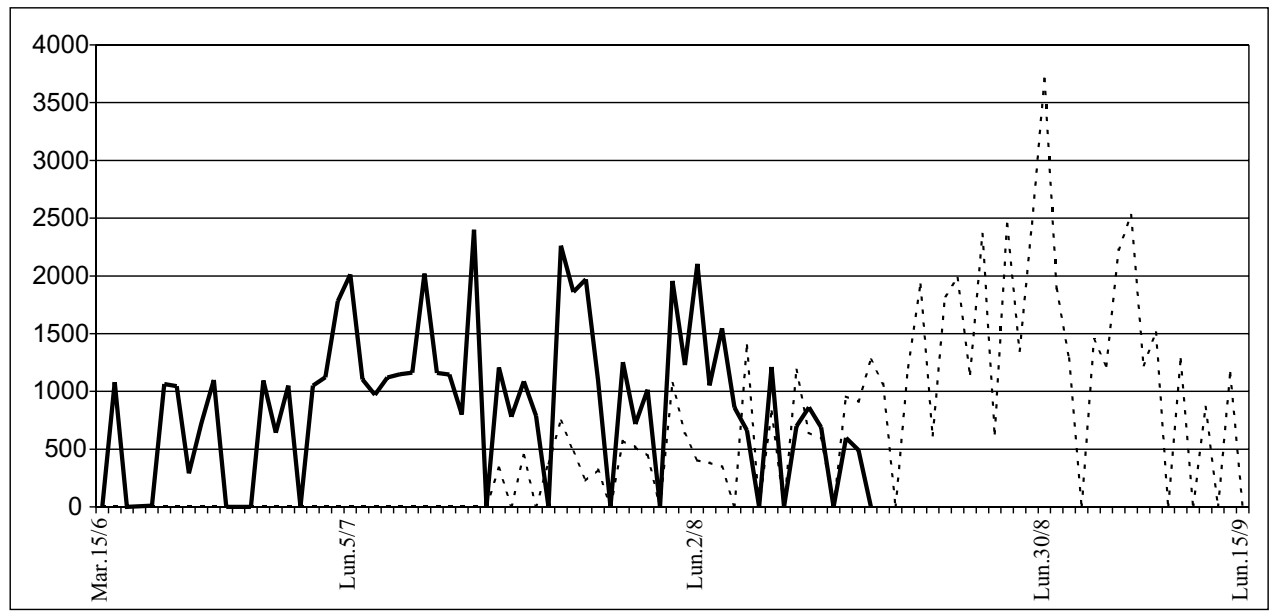

GráfICo 2. Evolución diaria del número de pasajeros y vehículos que han embarcado en el puerto de Alicante durante la Operación Paso del Estrecho de 1999. Línea continua: Operación Salida; línea discontinua: Operación Retorno. FUENTE: Memoria de la Operación Paso del Estrecho, Unidad de Protección Civil de la Subdelegación del Gobierno Civil en Alicante.

\section{Tráfico y comercio ligado a los argelinos en la ciudad de Alicante}

Las tendencias que hasta el momento nos muestran el gráfico 1 y el cuadro 1 no parecen indicar que a corto o medio plazo vaya a disminuir el paso de magrebíes por el puerto Alicante. Cierto es que el reciente incremento se debe sobre todo al tránsito veraniego de inmigrados en Europa. El día que, tarde o temprano, se reabra la frontera terrestre entre Argelia y Marruecos la alternativa del regreso por Marruecos volverá a ser posible y el puerto de Almería recuperará la parte de transeúntes argelinos que le corresponde de manera natural ${ }^{28}$. Esta situación circunstancial no nos debe de hacer olvidar que también ha aumentado el movimiento de argelinos durante el resto del año, el de los comerciantes y transportistas que vienen a Alicante a comprar. El contacto directo con Orán ha producido desde siempre intercambios comerciales, culturales o de personas. Actualmente durante la mayor parte del año los alicantinos perciben un ir y venir de transportistas cargados de paquetes entre el puerto y los bazares, bares y pensiones del centro de la ciudad. Se trata de un trasiego comercial sobre el que no hay datos objetivos y cuyo trasfondo general es un comercio, en gran medida irregular, destinado a alimentar una economía paralela de bienes de consumo en Argelia.

\subsection{El movimiento en la estación portuaria}

Cada vez que viene el barco se repite en la zona del puerto y en las calles del centro de la ciudad un movimiento de personas y paquetes; los comerciantes y transportistas que

28 La alternativa de Almería será incluso más atractiva que antes del cierre de la frontera puesto que desde entonces se ha creado la línea Almería-Nador. El no pasar por Melilla ahorrará a los inmigrados argelinos el paso siempre azaroso de una aduana magrebí. 
vienen a la ciudad suelen seguir una misma rutina. El barco suele atracar puntualmente a Alicante a las 8.00 de la mañana, hora a partir de la cual la autoridad portuaria ${ }^{29}$ establece tarifas diurnas. Entre el primer y el último automóvil en pasar el control de aduana puede transcurrir fácilmente más de una hora y media; es un tiempo que no están dispuestos a perder esperando en la cola los transportistas que vienen con las horas contadas para comprar y cargar la mercancía y marcharse por la tarde en el mismo barco. Esto justifica la extraña impaciencia con la que invariablemente desembarcan los vehículos y lleva a entender que éstos vienen absolutamente estratificados en la bodega del barco, de manera a salir primero los transportistas que vienen a comprar y luego los inmigrados que van a Francia. Es lo que de hecho se observa durante el desembarco, al principio se contabilizan más camionetas de transportistas mientras que al final son más los coches familiares de inmigrados con matrícula francesa. Durante este tiempo el papel de la Guardia Civil se limita en principio a controlar los documentos y a buscar, sobre todo en los coches que no vienen vacíos, con la ayuda de un perro, drogas o personas.

Las actuaciones de los transportistas están visiblemente optimizadas, tienen el tiempo, el dinero y los movimientos previstos; muchos de ellos vienen organizados en cuadrillas de hasta 5 ó 6 personas que llegan en un coche o en una furgoneta; cada uno de ellos transportará tantos bultos como pueda mientras que el vehículo será llenado de paquetes. Tras pasar el control de policía salen al muelle donde esperan varias personas, españolas y magrebíes, que en Alicante sirven de contacto a los transportistas más profesionales. Los vehículos son aparcados en el mismo muelle, un lugar donde teóricamente está prohibido pero donde los transportistas pueden vigilarse el vehículo unos a otros. Luego salen hacia la ciudad provistos de bolsas o de carritos para empezar a hacer los viajes de ida y vuelta entre los bazares de la ciudad y el puerto. Más tarde los coches no tardan en desaparecer para distribuirse por la provincia.

Durante todo el día hay movimiento de personas que van y vienen entre la ciudad y la estación portuaria. A partir de cierta hora aparece los que se dedica a empaquetar la mercancía, de manera que cada persona pueda transportar un máximo de fardos, mientras, los vehículos van llegando, a veces tan cargados de todo tipo de productos que apenas dejan espacio para el conductor. A la hora de embarcar, la impaciencia que había por la mañana en cruzar la aduana se torna parsimonia para la desesperación de los guardias portuarios, los coches de inmigrados no tienen entonces ningún problema en pasar los primeros. En el desconcierto de coches y personas es difícil cuantificar cuantos de los que han venido por la mañana se van esa misma tarde. Todas las personas interrogadas dicen que normalmente los transportistas se quedan en Alicante algunos días, hasta el siguiente barco, sin embargo el reducido número de hostales y pensiones que aceptan transportistas argelinos en Alicante no pueden dar cabida a las muchas personas que llegan en cada barco, por lo que es de suponer que una parte considerable de los que vienen por la mañana se irán el mismo día.

En los momentos previos al embarque se distingue bien el abanico de personas que realizan estas exportaciones invisibles, desde los «independientes», es decir argelinos que compran por su cuenta para su familia o para revender entre los conocidos, a los «profesionales» que van cargados al límite y que están visiblemente muy sistematizados. A este respecto hay que decir que estos últimos miran con creciente recelo a inmigrados e «independientes». Para el transportista profesional que vive de este comercio son, en efecto, una peligrosa competencia, puesto que en conjunto introdu-

29 Fuera de los horarios normales de apertura (de 8 a 20 horas) las tarifas del puerto son mayores; esta es sin duda la razón por la que, fuera del verano, nunca hay barco los domingos ni los días festivos en Alicante. 
cen en Argelia una cantidad considerable de $\operatorname{productos}^{30}$ y al viajar en menos ocasiones tienen individualmente menos problemas para cruzar la frontera; les acusan de transportar cada vez más productos para sus familias y conocidos restringiendo así sus circuitos de distribución.

\subsection{El desarrollo de los bazares en el centro de Alicante}

El incremento del movimiento de argelinos, así como el de la inmigración magrebí, ha multiplicado el número de bares, bazares y pensiones con clientela magrebí en el centro de la ciudad. Estos locales son la parte visible de toda una «economía de bazares» que se está dando en Alicante. La definición de «bazar» no resulta evidente a tenor de la gran diversidad de comercios que llevan ese nombre. En nuestro caso son los locales que compran directamente a las fábricas y a los almacenes productos a bajo precio (a veces pasados de temporada o incluso defectuosos) para revenderlos al por mayor, con o sin factura, a una clientela mayoritariamente extranjera.

Todos estos comercios se concentran en el centro de Alicante, la gran mayoría en las calles próximas, y a menudo tristes, que hay a ambos lados de la Rambla de Méndez Núñez cerca de la zona del puerto (gráfico 3). Sólo los bazares más consolidados se encuentran en los ejes transitados, aunque nunca en las grandes calles comerciales. Los transportistas suelen frecuentar siempre los mismos lugares. En los demás locales hay a veces un fuerte rechazo hacia ellos, aún más palpable en las pensiones y en los hostales donde «los paqueteros» - así les denominan algunos hosteleros- no suelen ser tolerados por ser, como mínimo, «ruidosos».

Los bazares no suelen llamar la atención por que son poco llamativos. Algunos incluso o no tienen ningún distintivo exterior de su condición de bazar o está totalmente desfasada. No lo necesitan por que su clientela sabe muy bien a donde va, es una clientela que, en el caso de los transportistas profesionales, viene con todas sus actividades previstas y controladas: los precios, lo que van a comprar, el cambio de moneda, el viaje, el sueldo para el transportista. Entre los bazares cabe destacar los que se dedican a la exportación por medio de los argelinos y los que abastecen de género a los vendedores ambulantes, una actividad a la que en Alicante se dedican diversos colectivos de inmigrados (marroquíes, orientales y sobre todo senegaleses). Más cerca de la playa hay algunos que se dedican también a los turistas y a los inmigrados argelinos que vienen de Francia a esperar el barco. Estos tienen gran diversidad de productos, desde meros recuerdos para turistas magrebíes o europeos, a mantas y tapices que son los productos que más se suelen llevar los argelinos a su país. Estos locales se benefician normalmente del hecho de que los argelinos inmigrados en Francia compran en Alicante, en el camino de ida y en el de vuelta: cuando van de Francia a Argelia, para llevar regalos a sus familias, y cuando vuelven de Argelia a Francia, porque los precios siguen siendo mucho más interesantes en Alicante que en Francia.

A pesar de las quejas de los bazaristas cuando se les pregunta sobre la situación de sus negocios es evidente que, en líneas generales, se trata de una economía floreciente. Pocos datos objetivos permiten cuantificar este fenómeno pero resulta evidente que durante los años 1990 se han multiplicado los comercios de este tipo alterando de manera apreciable la apariencia de algunas calles del centro de la ciudad. La fuerte movilidad (de cierres y

30 Los regalos de los emigrados tienen una importancia casi cultural en las sociedades magrebíes; a su regreso los inmigrados son invariablemente esperados con regalos para todo la familia y allegados. 


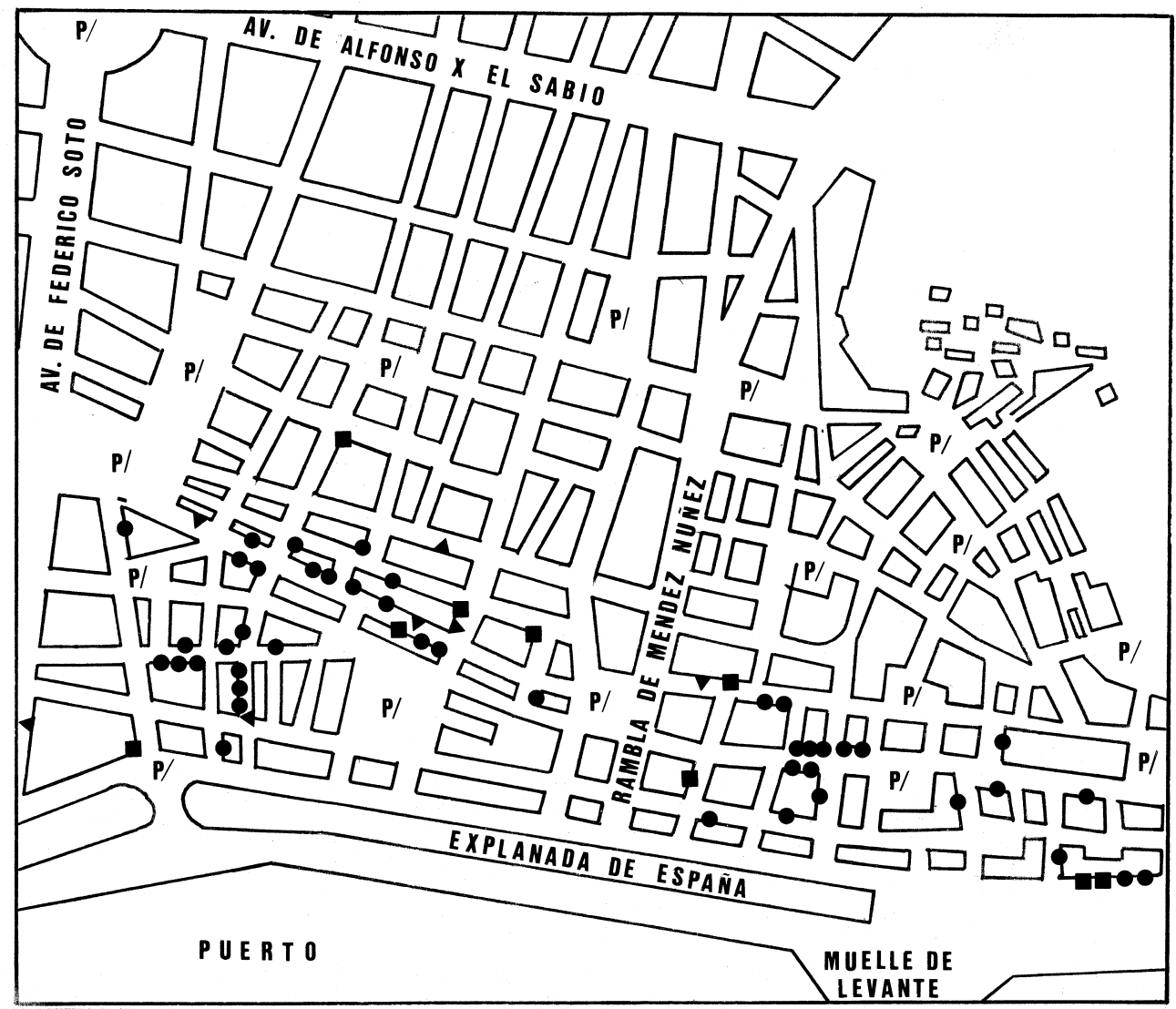

Gráfico 3. Bares (cuadrados), bazares (círculos) y otros comercios (triángulos) frecuentados por población de origen africano en el centro de Alicante. FUENTE: E.P.

aperturas) es una característica esencial de esta economía informal y versátil sobre todo en lo que atañe las exportaciones a Argelia. Es un fenómeno que la administración no parece controlar en sus aspectos globales, los datos del negociado de aperturas del Ayuntamiento de Alicante - la fuente oficial — no corresponden siempre con los comercios contabilizados en la calle. La guía telefónica contiene en sus páginas amarillas la entrada «bazares» pero incluye un espectro de comercios muy amplio, desde tiendas de disfraces y de «todo a 100» a grandes almacenes, lo que tampoco corresponde con la realidad: la guía de 199899 contiene para todo el municipio 38 bazares, menos de los que se han contabilizado sólo en unas cuantas calles del centro de la ciudad (gráfico 3). No obstante es bastante revelador que el número de bazares que vienen en la guía se haya duplicado durante la década de los años 1990 y que los nombres árabes de estos comercios hayan pasado de no existir en los años 1980, a ser una decena en 1998-99, una cuarta parte del total.

Todo este movimiento sólo se puede justificar con el aumento del número de inmigrados que trabaja en el comercio ambulante y con el incremento de los argelinos que transitan por Alicante o por lo menos de las mercancías que estos se llevan. 


\subsection{El móvil del tráfico}

El motivo de todo el tráfico que se describe es sin duda la simple presencia de la frontera social y económica que hay entre Europa y el Magreb. Una frontera entre dos países y unos intercambios que se alimentan de las diferencias y de los desequilibrios existentes entre ambos lados de dicha frontera. En este caso tenemos por un lado, España, un país desarrollado, y Alicante, una provincia que se caracteriza precisamente por el desarrollo de sus producciones de consumo, mientras que del otro lado está Argelia, un país cuya sociedad necesitada en numerosos aspectos cotidianos como el consumo.

A pesar de su pasado colonial, Argelia es, de los países del Magreb central, el menos abierto a Occidente y el que en las últimas décadas ha llevado una política más nacionalista. Las equivocadas apuestas económicas y demográficas que en el pasado hicieron sus gobiernos, le están pasando una factura pesada a la sociedad, compuesta en sus tres cuartas partes por jóvenes menores de 30 años. La producción de bienes de consumo argelina no puede, ni abastecer la sociedad, ni ser competitiva en el mercado interno ante la entrada regular e irregular de los productos occidentales. El Estado que durante muchos años se ha opuesto a la economía de mercado intenta salvaguardar la economía imponiendo altos aranceles lo que en la realidad incentiva el contrabando. Sólo recientemente se han tomado medidas para favorecer las importaciones.

La gran necesidad de artículos cotidianos de consumo se conjuga en Argelia más que en otros países con la crisis que conoce el país y con la fascinación que ejercen Europa y el modelo de vida occidental sobre aquella sociedad. Todo lo que viene de Europa, de España, de Alicante se puede vender en Argelia con valor añadido porque hay una gran demanda; esta demanda, gracias a la televisión y al retorno anual de los emigrados cargados de regalos, conoce muy bien lo que son los productos y el modo de vida occidentales a los que no tiene un acceso fácil. No importa ni la marca, ni la calidad, ni siquiera la presentación del artículo con tal de que sea de origen occidental y extranjero porque «si es extranjero, es bueno» ${ }^{31}$. Esta mezcla de necesidad y de esterofilia fundamenta todo este movimiento y explica que a los importadores, los que contratan a los transportistas, les resulte más rentable pagar, además del precio español del género, los sueldos, los visados, las propinas, el cambio de la divisa y el viaje de sus hombres, que pagar los altos aranceles que exige Argelia a la entrada de manufacturas extranjeras.

Esta situación es uno de los motivos que ha dado lugar en ese país a un crecimiento desenfrenado del contrabando en el que trabajan gran número de auténticos especialistas. Trabendo es un término surgido de la palabra contrabando para definir este tráfico [Diario Le Monde, 2 de julio de 1987, p. 7] que envenena la economía de Argelia. Es tal la importancia que tiene este comercio que en la Asamblea Nacional se llegó a plantear la posibilidad de legalizarlo [LÓPEZ GARCÍA, 1996: 254].

Cada barco que llega de Alicante a Orán viene cargado con productos destinados a alimentar esta demanda argelina. El paso de la aduana argelina es en teoría un momento delicado, ya que a partir de ciertas cantidades hay que abonar el dinero correspondiente a los aranceles. Los inmigrados no suelen tener demasiados problemas, llevan una cantidad y un tipo de artículos que es fácil justificar como regalos, sobre todo si le dejan su parte al aduanero. Los transportistas necesitan, o bien tener un pasaporte sin demasiados visados - algo que siempre facilita la entrada y la salida - o bien tener el contacto

31 En las palabras de un entrevistado. 
adecuado $^{32}$. Muchos de ellos tienen para ello un dominio importante de las influencias, de los sobornos, de los portadores del puerto, que les permite manejarse con soltura en esos momentos: el savoir faire necesario para pasar sin pagar los aranceles e introducir el género comprado en Alicante en las redes comerciales.

\section{Conclusión}

Durante las dos últimas décadas se observa como la ciudad y la sociedad alicantina se consolidan en su papel europeo y en un contexto en el que hay poco lugar para los intercambios humanos, culturales y económicos con Argelia, país con el que Alicante siempre ha tenido una intensa relación. En los años 1980 se dio una recuperación de dichos contactos pero muy ligada a una voluntad política por parte de la administración local, una voluntad que actualmente ha desaparecido por completo. En la década siguiente la inestabilidad de Argelia y la evolución de la sociedad española han terminado por reducir estos contactos al ámbito puramente comercial.

Sin embargo durante esta misma década Alicante se ha consolidado como el puerto de Argelia en España. El cierre de la frontera terrestre entre Argelia y Marruecos ha transformado esta ciudad en un importante punto de paso para el regreso a Argelia con lo que la línea Orán-Alicante es ahora la que más vehículos y pasajeros transporta por barco de cuantas cruzan el Mediterráneo desde la Península. A pesar del origen político de este incremento, es probable que la tendencia continúe a medida que aumente el número y mejore la situación de los residentes argelinos en España y que otros puertos, como el de Marsella, vayan perdiendo parte de su protagonismo tradicional y exclusivo para la emigración argelina y para las relaciones comerciales con este país.

En Alicante el movimiento de argelinos ha dado lugar a una economía de bazares y a unos intercambios que están transformando el centro urbano de la ciudad y creando un tipo de riqueza que las autoridades portuarias y municipales no parecen percibir. Este tráfico se hace a través de redes a menudo informales y de circuitos bien rodados de trabajadores transfronterizos (transportistas y portadores) que como verdaderas hormigas se dedican a exportar una diversidad ingente de productos de consumo occidentales a Argelia. A pesar de las estadísticas oficiales y de las actuales orientaciones políticas no parecen que en un futuro próximo vaya disminuir este tráfico que seguirá subsistiendo mientras no se reduzca los desequilibrios entre Argelia y Europa.

\section{Bibliografía}

CHAREF, Mohammed: La circulation migratoire marocaine: un pont entre deux rives, Ed. Sud Contact, Rabat, 1999, 237 p.

GAUTHIER, Cathérine: «Sociabilités et commercialisations des mobilités migratoires marocaines», Revue Européenne des Migrations internationales, Vol. 13, N 3, 1997, pp. 183-210.

GAUTHIER, Cathérine: «La route des marocains: les frontières d'un parcour de retour», Revue Européenne des Migrations internationales, Vol. 9, № 1, pp. 131-142.

LARRAMENDI, Miguel H. de: «Crónica hispano-magrebí», en LÓPEZ GARCÍA, Bernabé, España-Magreb, siglo XXI. Porvenir de una vecindad, Madrid, Ed. MAPFRE, 1992, pp. 345-372.

32 Es un fenómeno que salvando algunas diferencias presenta numerosos paralelos con el que se da entre Marruecos y Ceuta y Melilla, dos ciudades exentas de ciertos impuestos que están abasteciendo por medio del contrabando una gran parte del norte del país. En grandes ciudades como Tetuán y Ksar el Kebir hay zocos, conocidos por todo el mundo en los que sólo se vende artículos importados de esta manera desde las dos ciudades autónomas. 
LÓPEZ GARCÍA, Bernabé (dir.): Atlas de la inmigración magrebí en España, Madrid, Ed. Universidad Autónoma de Madrid, 1996, 252 p.

SIMON, Gildas: Geodynamiques des migrations internationales, Paris, Ed. PUF, 1996.

STORA, Benjamín: Histoire de l'Algérie depuis l'indépendance, Paris, Ed. La Découverte, Coll. Repères, 1994, 121 p.

TARRIUS, Alain: Les fourmis d'Europe. Migrants riches, migrants pauvres et nouvelles villes internationales, Ed. l'Harmattan, 1992, Paris, 207 p.

TARRIUS, Alain: Arabes de France dans l'économie mondiale souterraine, Ed. de l'Aube, 1995, La Tour-d'Aigues, 219 p.

VALERO ESCANDELL, José Ramón: La inmigración extranjera en Alicante, Alicante, Ed. Instituto Juan-Gil Albert y Diputación Provincial de Alicante, 1992.

VARGAS LLOVERA, María Dolores: «La inmigración africana de venta ambulante. El caso de Alicante», en CHECA, Francisco (Ed.), Africanos en la otra orilla, Ed. Icaria, Col. Antrazyt, Barcelona, 1998, pp. 61-77.

\section{Publicaciones periódicas}

Ministerio de Asuntos Sociales. Dirección General de Migraciones: Anuario de migración 1997, Madrid.

Ministerio del Interior. Dirección General de Protección Civil: Memorias de la Operación Paso del Estrecho, 1997, 1998 y 1999, Madrid.

SOPEMI. OCDE: Tendances des Migrations Internationales. Rapport Annuel, Ed. OCDE, 1999. 